University of Nebraska - Lincoln

DigitalCommons@University of Nebraska - Lincoln

Biological Systems Engineering: Papers and

Publications

Biological Systems Engineering

2017

Crop canopy sensor orientation for late season nitrogen determination in corn

T. M. Shaver

Greg Kruger

Daran Rudnick

Follow this and additional works at: https://digitalcommons.unl.edu/biosysengfacpub

Part of the Bioresource and Agricultural Engineering Commons, Environmental Engineering Commons, and the Other Civil and Environmental Engineering Commons

This Article is brought to you for free and open access by the Biological Systems Engineering at

DigitalCommons@University of Nebraska - Lincoln. It has been accepted for inclusion in Biological Systems

Engineering: Papers and Publications by an authorized administrator of DigitalCommons@University of Nebraska Lincoln. 


\title{
Crop canopy sensor orientation for late season nitrogen determination in corn
}

\author{
T. M. Shaver, G. R. Kruger, and D. R. Rudnick \\ University of Nebraska-Lincoln, West Central Research and Extension Center, \\ North Platte, NE, USA \\ Correspondence - T. M. Shaver tshaver2@unl.edu University of Nebraska-Lincoln, West \\ Central Research and Extension Center, North Platte, NE, USA.
}

\begin{abstract}
Increasing nitrogen use efficiency (NUE) in irrigated corn production is of great importance to overall agricultural sustainability. Studies have shown that crop canopy sensors can aid in this pursuit as they allow for the determination of nitrogen $(\mathrm{N})$ requirements in split applications later in the growing season. Fertigation can also increase NUE as many split applications can be conducted. If crop canopy sensors could be used to direct $\mathrm{N}$ fertigation rates, overall NUE may be increased even further. However, in some cases, $\mathrm{N}$ differences may need to be determined later in the growing season after corn has tasseled, which can cause issues with crop canopy sensor readings. Therefore, a study was initiated to evaluate the potential of a crop canopy sensor to differentiate between $\mathrm{N}$ levels at two corn (Zea mays) growth stages (R1 and R3) after the corn had tasseled. The sensor was placed in three orientations to evaluate which orientation best determined the corn $\mathrm{N}$ status across two sensor-calculated indices while avoiding taking measurements involving the corn tassel. These orientations were (1) nadir, between corn rows (above canopy), (2) $45^{\circ}$ off nadir within the corn canopy (below corn tassel), and (3) $90^{\circ}$ off nadir
\end{abstract}

Published in Journal of Plant Nutrition 40:15 (2017), pp 2217-2223 doi:10.1080/01904167.2017.1346681

Copyright (C) 2017 Taylor \& Francis Group, LLC. Used by permission.

Submitted 22 February 2016; accepted 31 August 2016 
within the corn canopy (below corn tassel). The results of this study show that $\mathrm{N}$ differences in late season corn can be determined by utilizing crop canopy sensors in an inter-row orientation. Results also show that the red edge normalized difference vegetation index (ReNDVI) index is superior to the normalized difference vegetation index (NDVI) index for late season $\mathrm{N}$ determinations in corn. These results suggest that crop canopy sensors could be an effective tool for determining $\mathrm{N}$ requirements of corn late in the growing season.

Keywords: crop canopy sensors, nitrogen

\section{Introduction}

Crop canopy sensors have been used for some time for the determination of corn nitrogen (N) status, and numerous publications have shown that remote sensors are quite effective in this capacity (Shaver, Khosla, and Westfall 2010, 2011; Hatfield et al. 2008). Crop canopy sensors operate by directing light (within specific wavelength bands) at the crop canopy and measuring the amount of light reflected (Inman, Khosla, and Mayfield 2005). These values are then used to calculate indices that are used to determine differences in plant growth related to specific characteristics, e.g., plant N. Essentially greater leaf area and green plant biomass levels result in higher reflectance and index values (Inman, Khosla, and Mayfield 2005). Because leaf area and green biomass are directly related to the $\mathrm{N}$ content of the plant, higher reflectance values are related to higher plant $\mathrm{N}$ content. These properties allow canopy sensors to be a valuable tool in determining relative plant $\mathrm{N}$ status and side-dress $\mathrm{N}$ application rates (Shiratsuchi et al. 2011).

The effectiveness of crop canopy sensors to determine the N status of corn has been well established. Traditionally, the use of sensors to determine $\mathrm{N}$ application rates occurs early in the growing season around the V10-V12 corn growth stages prior to tassel emergence. One reason for this is due to equipment constraints as high clearance equipment is needed to apply sensor based $\mathrm{N}$ rates. This equipment is generally only effective up until the V12 corn growth stage. However, the management practice of applying $\mathrm{N}$ through fertigation opens up the potential to use sensors later in the growing season, even post-tassel, to determine $\mathrm{N}$ needs of the crop longer into the growing season. It has been shown that $\mathrm{N}$ applications up to the corn $\mathrm{R} 3$ growth stage can 
increase grain yield in cases of extreme N deficiency (Binder, Sander, and Walters 2000). Using sensors to direct split $\mathrm{N}$ applications has the potential to greatly increase nitrogen use efficiency (NUE) as applications are spread throughout the growing season in smaller quantities as the crop needs it. If crop canopy sensors are to be used to make $\mathrm{N}$ application decisions later in the season, the sensors may need to be used after the corn plant has tasseled. This may present a problem as previous studies have recorded abnormal deviations in reflectance values after the corn has tasseled (Martin et al. 2007). To alleviate this issue, the sensor may need to be moved to a position where the effect of the tassel is eliminated or at least reduced.

Therefore, a study was initiated to evaluate the potential of a commercially available crop canopy sensor to determine late season $\mathrm{N}$ status at two growth stages after corn tasseling (R1 and R3) (Abendroth et al. 2011). The sensor was used in three distinct orientations to evaluate which orientation best determined the differences in corn while avoiding tassel effects. The first orientation minimized tassel effect, while the other two sensor orientations avoided taking measurements involving the corn tassel entirely. The orientations were (1) nadir, between corn rows (75 $\mathrm{cm}$ above canopy), (2) $45^{\circ}$ off nadir within the corn canopy (below corn tassel), and (3) $90^{\circ}$ off nadir within the corn canopy (below corn tassel). Two sensor calculated indices (red edge normalized difference vegetation index (ReNDVI) and normalized difference vegetation index (NDVI)) were compared within each sensor orientation at each $\mathrm{N}$ level.

\section{Materials and methods}

\section{Sites}

Two site locations were used for data collection in the summer of 2010 for this study. Site 1 was located in North Platte Nebraska (west central NE) at the University of Nebraska-Lincoln West Central Research and Extension Center. This site is located at $41^{\circ} 05^{\prime} 12.43^{\prime \prime} \mathrm{N}, 100^{\circ} 46^{\prime}$ 22.50" W and is classified as a Hord silt loam (fine-silty, mixed, superactive, mesic Cumulic Haplustoll) (Soil Survey Staff 2012). Site 2 was located near Imperial Nebraska (south west NE) on a cooperator's 
field. This site is located at $40^{\circ} 29^{\prime} 41.98^{\prime \prime} \mathrm{N}, 101^{\circ} 36^{\prime} 30.68^{\prime \prime} \mathrm{W}$ and is classified as a Goshen silt loam (fine-silty, mixed, superactive, mesic Pachic Argiustoll) (Soil Survey Staff 2012). Both sites had 0-1\% slope and were in irrigated continuous corn for several years prior to this study.

\section{Experimental design/treatments}

Both sites used a split-plot randomized complete block design with four replications. Site 1 had four N treatments of o, 75, 150, and 225 $\mathrm{kg} \mathrm{ha}^{-1}$. Site 2 had three $\mathrm{N}$ treatments of 150,200 , and $250 \mathrm{~kg} \mathrm{ha}^{-1}$. Site 2 had a higher yield potential and therefore had a higher maximum $\mathrm{N}$ rate. Additionally, Site 2 did not include a check rate as this was a farmer's field and the cooperator did not want to limit yields to this level. All N applications were made as broadcast urea (46-O-O) as close to corn emergence as possible. These treatments resulted in an $\mathrm{N}$ gradient from high to low at each site. Site 1 had sub-surface drip irrigation with treatment plots of $75 \mathrm{~m}$ in length and $9 \mathrm{~m}$ in width. Site 2 was under center-pivot irrigation with treatment plots of $9 \mathrm{~m}$ in length and $18 \mathrm{~m}$ in width.

\section{Sensor data collection}

Data for this study was collected at the R1 and R3 corn growth stages (Abendroth et al. 2011) at both sites using a Holland Scientific Crop Circle 430 Crop Canopy Sensor (Holland Scientific, Lincoln, NE, USA). Data was collected from each $\mathrm{N}$ treatment at each site. The sensor was placed by hand in three orientations within each plot and data was collected for a period of $10 \mathrm{~s}$ resulting in approximately 100 data points for each plot. The three sensor orientations were: (1) nadir, between corn rows (inter-row) ( $75 \mathrm{~cm}$ above canopy), (2) $45^{\circ}$ off nadir within the corn canopy (below corn tassel), and (3) $90^{\circ}$ off nadir within the corn canopy (below corn tassel). For orientations 2 and 3, the sensor was placed against a row of corn directly below the tassel with the sensor directed at the adjacent row. This created a sensing distance similar to treatment 1 (about $75 \mathrm{~cm}$ ). 


\section{Indices}

The Holland Scientific Crop Circle ACS-430 Crop Canopy Sensor records reflectance data in three wavelengths. These wavelengths are red band reflectance $\left(\rho_{\mathrm{R}}\right)$ (670 $\left.\mathrm{nm}\right)$, near infrared band reflectance $\left(\rho_{\mathrm{NIR}}\right)(780 \mathrm{~nm})$, and red-edge band reflectance $\left(\rho_{\mathrm{RE}}\right)(730 \mathrm{~nm})$ (Holland Scientific 2010). The sensor automatically calculates two indices; normalized difference vegetation index (NDVI) and red-edge normalized vegetation index (ReNDVI). The equations to calculate each of the indices are listed below:

$$
\begin{gathered}
\mathrm{NDVI}=\rho_{\mathrm{NIR}}-\rho_{\mathrm{R}} / \rho_{\mathrm{NIR}}+\rho_{\mathrm{R}} \\
\mathrm{ReNDVI}=\rho_{\mathrm{NIR}}-\rho_{\mathrm{RE}} / \rho_{\mathrm{NIR}}+\rho_{\mathrm{RE}}
\end{gathered}
$$

Normalized difference vegetation index has been shown to accurately determine differences in corn growth related to $\mathrm{N}$ fertilization as well as plant N content (Shaver, Khosla, and Westfall 2011, 2010) and is used extensively within remote sensing for determination of plant greenness. ReNDVI is not as commonly used but has been shown to relate highly to plant biomass (Mutanga and Skidmore 2004), which also relates to plant N. Both indices were tested in this study across all three sensor orientations.

\section{Statistical analysis}

Statistical analysis was conducted using Statistical Analysis Software (SAS) (SAS 2015). All regressions were conducted using the procedure Proc REG. For all means calculations, the procedure Proc Means was used. All figures were created using Microsoft Excel (Microsoft Corporation, Pullman, WA).

\section{Results and discussion}

\section{Site 1}

Crop canopy sensor readings were collected at the R1 and R3 corn growth stages in three sensor orientations (nadir, between corn rows; 

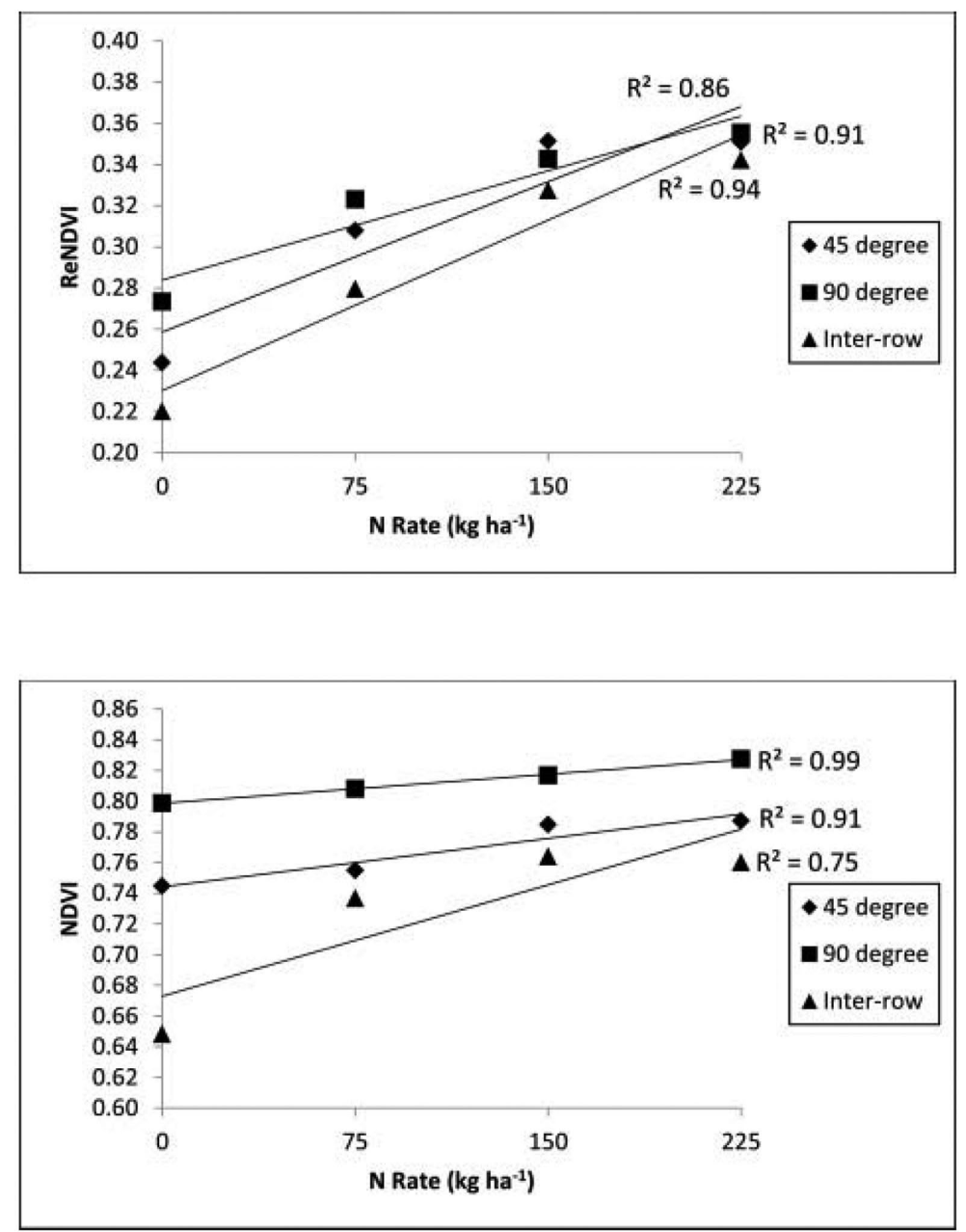

Figure 1. Red edge normalized difference vegetation index (ReNDVI) and normalized difference vegetation index (NDVI) as affected by applied nitrogen (N) rate and crop canopy sensor orientation at the R1 corn growth stage at site 1 .

$45^{\circ}$ off nadir within the corn canopy; and $90^{\circ}$ off nadir within the corn canopy) at site 1 . Two sensor calculated indices were compared (ReNDVI and NDVI) at each orientation. At the R1 growth stage, results showed that both the ReNDVI and NDVI indices were able to distinguish differences related to $\mathrm{N}$ in the corn at each sensor orientation (Figure 1). The ReNDVI had $R^{2}$ values of $0.86,0.91$, and 0.94 at the $45^{\circ}, 90^{\circ}$, and inter-row sensor orientations, respectively. This suggests that any of the tested orientations would be effective in determining $\mathrm{N}$ differences in corn at the R1 growth stage using ReNDVI. Results 

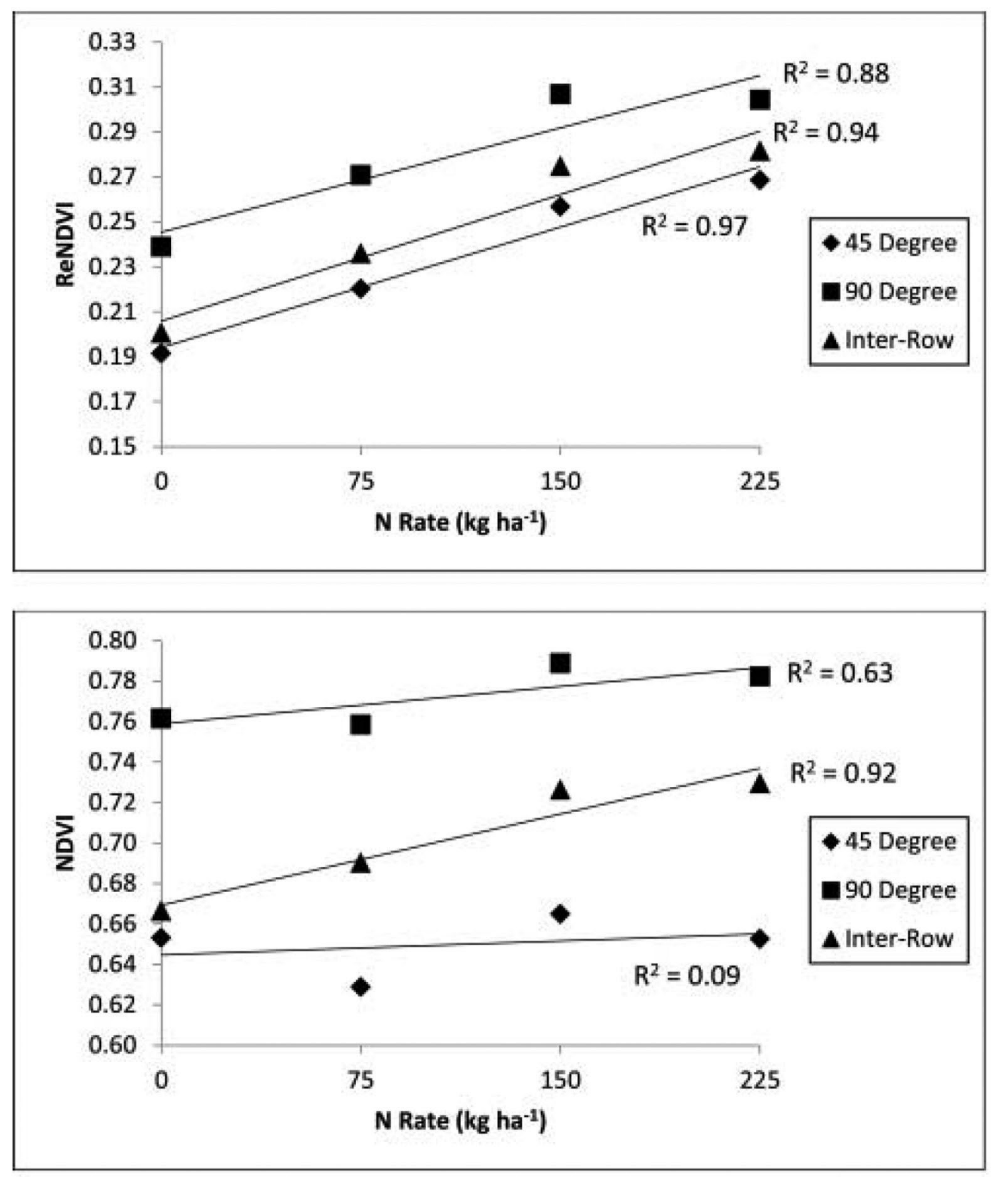

Figure 2. Red edge normalized difference vegetation index (ReNDVI) and normalized difference vegetation index (NDVI) as affected by applied nitrogen (N) rate and crop canopy sensor orientation at the R3 corn growth stage at site 1 .

for the NDVI index at the R1 growth stage showed high $R^{2}$ values for the $45^{\circ}$ and $90^{\circ}$ orientations ( 0.91 and 0.99 , respectively) and then a drop off to 0.75 using the inter-row sensor orientation. This suggests that NDVI is not as effective as ReNDVI at the R1 growth stage using the inter-row orientation.

At the R3 corn growth stage, similar results were observed using the ReNDVI index (Figure 2). High $R^{2}$ values were observed across all sensor orientations tested $\left(0.97,0.88\right.$, and 0.94 at the $45^{\circ}, 90^{\circ}$, and inter-row sensor orientation, respectively). Results for the NDVI index showed that only the inter-row sensor orientation produced a high $R^{2}$ value (0.92). The $45^{\circ}$ and $90^{\circ}$ orientations had $R^{2}$ values of 0.09 and 
0.63 , respectively. Again, this suggests that the ReNDVI index is better suited to determine later season $\mathrm{N}$ differences in corn. Additionally, all sensor orientations tested proved to be effective at site 1 in determining $\mathrm{N}$ differences when using the ReNDVI index.

The NDVI index has been shown to have limitations especially due to potential saturation (Mutanga and Skidmore 2004). While saturation levels were not reached in this study, overall NDVI values were greater than ReNDVI values. With late season measurements, the sensor was being used in a full corn canopy, and the R3 measurements were less accurate than the R1 measurements when using NDVI. These results suggest that NDVI becomes less effective later in the growing season.

\section{Site 2}

At site 2, sensor orientation had a greater effect on calculated indices than were observed at site 1 . At the R1 corn growth stage, $R^{2}$ values were quite low at the $45^{\circ}$ (o.29) and $90^{\circ}$ (o.44) sensor orientations for ReNDVI (Figure 3). This was also the case for the NDVI index as the $45^{\circ}$ orientation had an $R^{2}$ value of 0.29 . The $90^{\circ}$ sensor orientation had an $R^{2}$ of 0.79. However, the sensor recorded a lower NDVI value at the $250 \mathrm{~kg} \mathrm{ha}^{-1} \mathrm{~N}$ rate than at the 150 or $200 \mathrm{~kg} \mathrm{ha}^{-1}$ rates resulting in a negative trend. Only the ReNDVI inter-row orientation reading resulted in a high $R^{2}$ value at the R1 corn growth stage at site 2 (0.98). The NDVI $R^{2}$ value at R1 was 0.75 , again suggesting that ReNDVI is a better index for the determination of $\mathrm{N}$ differences in corn later in the growing season.

At the R3 corn growth stage, results were similar to those observed at the R1 stage (Figure 4). The ReNDVI $R^{2}$ values were quite low at 0.12 and 0.40 for the $45^{\circ}$ and $90^{\circ}$ orientations, respectively. Values were also quite low using NDVI at the $45^{\circ}$ (0.16) and $90^{\circ}$ (0.24) orientations. Using the inter-row sensor orientation again had the highest $R^{2}$ values with ReNDVI (0.99) and NDVI (0.85) with the ReNDVI being the highest overall.

At site 2, the yield potential was much greater than at site 1 , and overall biological growth was greater at site 2 than at site 1 . This may explain why orientation was more important at site 2 than at site 1 . Moving the sensor into the canopy with the $45^{\circ}$ and $90^{\circ}$ orientations 

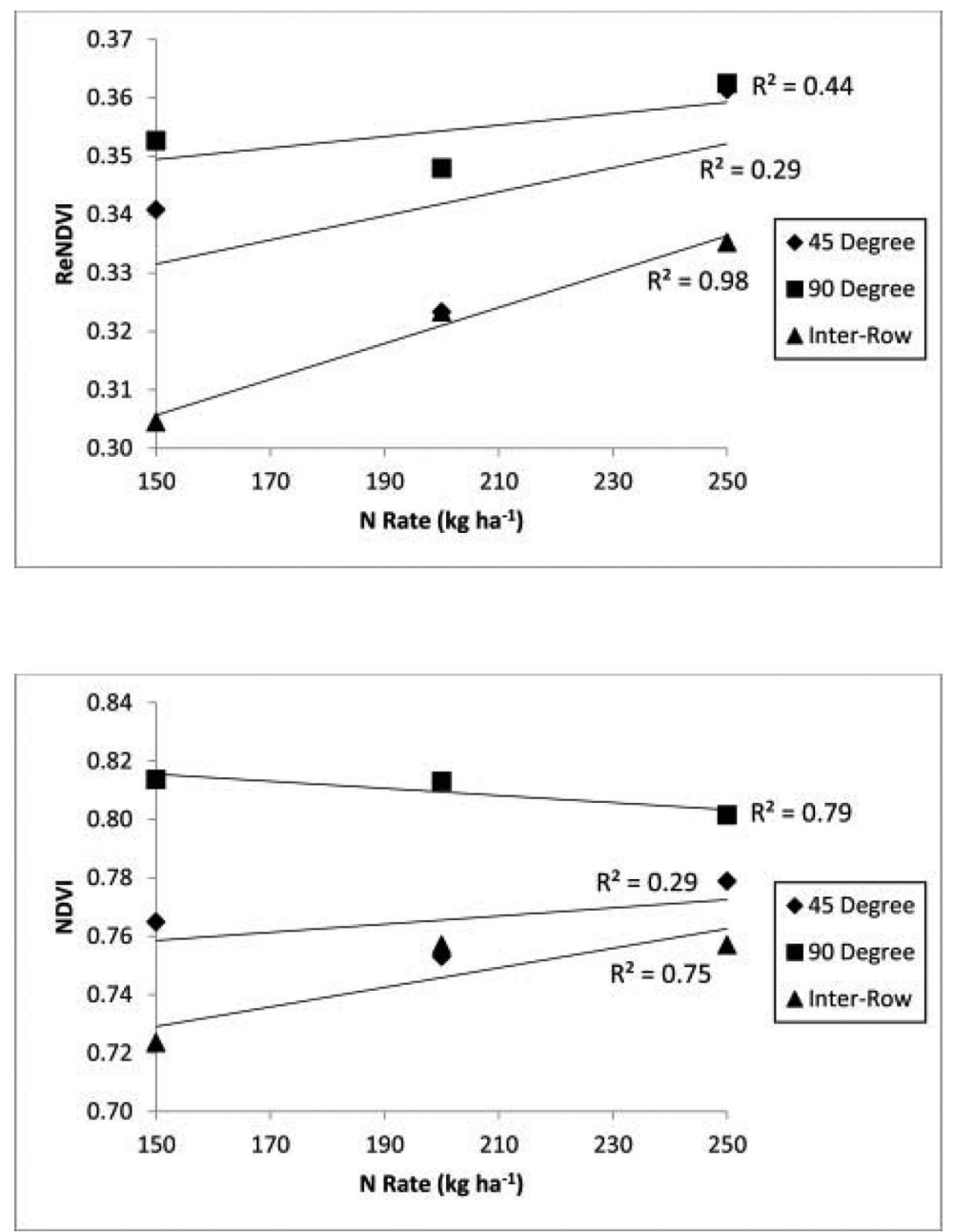

Figure 3. Red edge normalized difference vegetation index (ReNDVI) and normalized difference vegetation index (NDVI) as affected by applied nitrogen (N) rate and crop canopy sensor orientation at the R1 corn growth stage at site 2 .

proved to be quite challenging with larger plants. Keeping leaves from interfering with sensor readings was far more difficult at site 2 than at site 1 due to the increased growth. This may explain why only the inter-row orientation was effective at site 2 , while all orientations were effective at site 1 (with ReNDVI).

Overall, the inter-row orientation using ReNDVI was most effective in determining $\mathrm{N}$ differences in corn at both the R1 and R3 growth stages at both sites tested in this study. The ReNDVI index had $R^{2}$ 

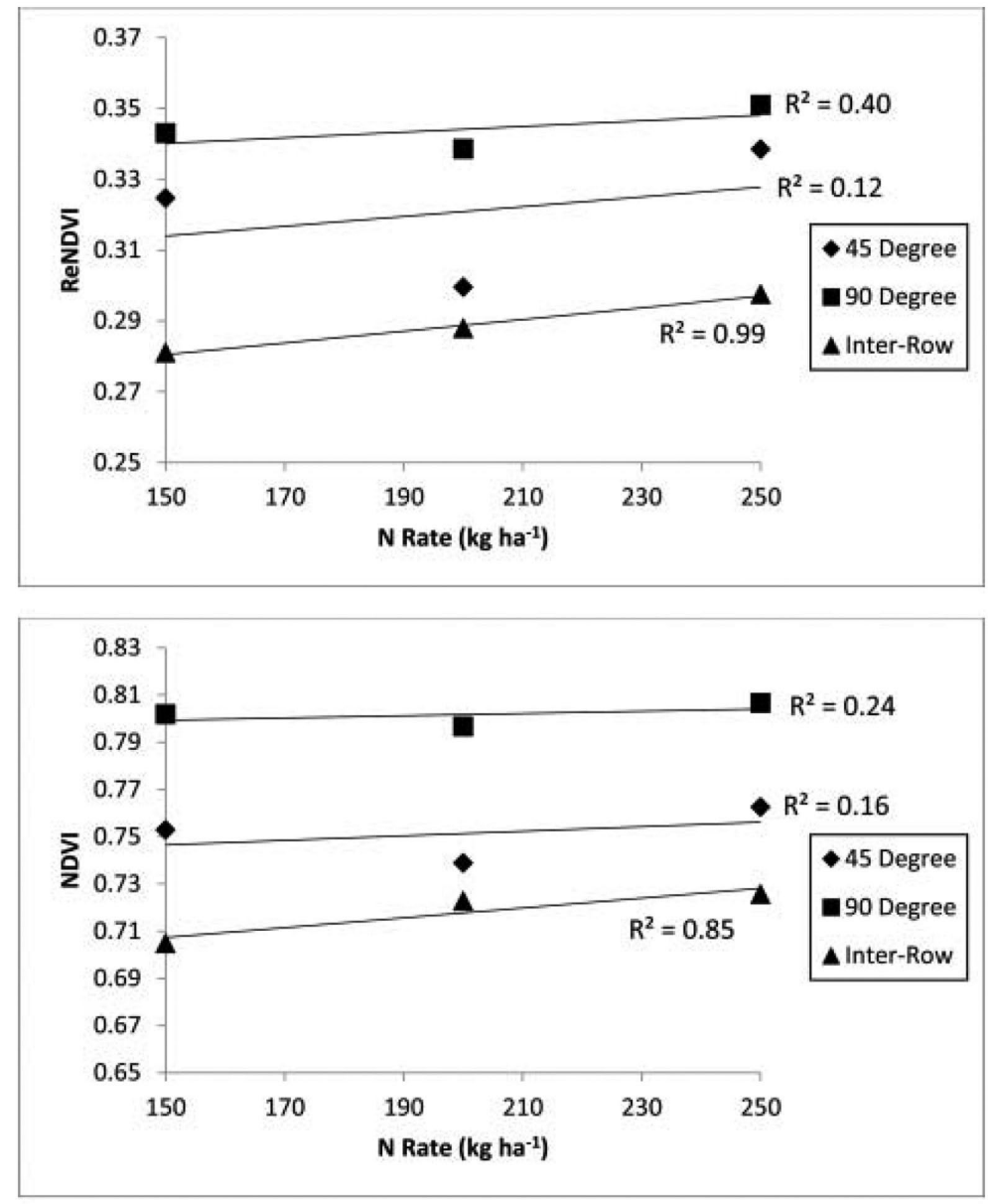

Figure 4. Red edge normalized difference vegetation index (ReNDVI) and normalized difference vegetation index (NDVI) as affected by applied nitrogen (N) rate and crop canopy sensor orientation at the R3 corn growth stage at site 2 .

values of at least 0.94 in all instances when it was used with the inter-row orientation. The NDVI index used in the inter-row orientation was also effective but less so than the ReNDVI index as it had $R^{2}$ values ranging from 0.75 to 0.92 . Overall, the ReNDVI index performed better than the NDVI index in all instances suggesting that the ReNDVI index is better for the determination of $\mathrm{N}$ differences in late season corn. Additionally, the inter-row orientation was effective in determining $\mathrm{N}$ differences in all instances tested, while this was not the case with the $45^{\circ}$ and $90^{\circ}$ orientations. 


\section{Conclusions}

Increasing NUE and decreasing potential environmental degradation from over application of $\mathrm{N}$ fertilizers are of great importance to the sustainability of Great Plains agriculture. This is especially true in irrigated corn production as corn uses large quantities of $\mathrm{N}$ to maximize yields. Crop canopy sensors are a useful tool in this pursuit as they can aid in determining $\mathrm{N}$ requirements later in the season allowing for split applications of $\mathrm{N}$ fertilizer. Fertigation may also be an important management practice in increasing NUE as this practice allows for many split applications of $\mathrm{N}$ throughout the growing season. Incorporating crop canopy sensors with fertigation has the potential to enhance NUE; however, using the sensors once the corn has tasseled can be challenging. The results of this study showed that $\mathrm{N}$ differences in late season corn can be determined by utilizing crop canopy sensors in an inter-row orientation (thereby negating the effect of the tassel). Results also showed that the ReNDVI index is superior to the NDVI index for late season N determinations in corn. These results suggest that crop canopy sensors could be an effective tool for determining $\mathrm{N}$ requirements of corn late in the growing season allowing for increased split applications through fertigation, thereby increasing overall NUE and agronomic input efficiency.

\section{References}

Abendroth, L. J., R. W. Elmore, M. J. Boyer, and S. K. Marlay. 2011. Corn growth and development, PMR 1009. Ames Iowa: Iowa State University Extension.

Binder, Darren L., Donald H. Sander, and Daniel T. Walters. 200o. Maize response to time of nitrogen application as affected by level of nitrogen deficiency. Agronomy Journal 92 (6):1228-36.

Hatfield, J. L., A. A. Gitelson, J. S. Schepers, and C. L. Walthall. 20o8. Application of spectral remote sensing for agronomic decisions. Agronomy Journal 100:S-117-31.

Holland Scientific. 2010. Crop Circle ACS-43o User's Guide. Lincoln, NE: Holland Scientific, Inc.

Inman, D., R. Khosla, and T. Mayfield. 2005. On-the-go active remote sensing for efficient crop nitrogen management. Sensor Review 25 (3):209-16.

Martin, K. L., K. W. Girma, R. K. Freeman, B. Teal, D. B. Tubana, D. B. Arnall, B. Chung, O. Walsh, J. B. Solie, M. L. Stone, and W. R. Raun. 2007. Expression 
of variability in corn as influenced by growth stage using optical sensor measurements. Agronomy Journal 99:384-9.

Mutanga, O., and A. K. Skidmore. 2004. Narrow band vegetation indices overcome the saturation problem in biomass estimation. International Journal of Remote Sensing 25 (19):3999-4014.

SAS Institute, Inc. 2015. SAS user's guide. Cary NC: SAS Institute, Inc.

Shaver, T. M., R. Khosla, and D. G. Westfall. 2011. Evaluation of two crop canopy sensors for nitrogen variability determination in irrigated maize. Journal of Precision Agriculture 12:892-904.

Shaver, T., R. Khosla, and D. G. Westfall. 2010. Evaluation of two groundbased active remote sensors for $\mathrm{N}$ variability determination in maize under greenhouse conditions. Soil Science Society of America Journal 74:2101-8.

Shiratsuchi, L., R. Ferguson, J. Shanahan, V. Adamchuk, D. Rundquist, D. Marx, and G. Slater. 2011. Water and nitrogen effects on active canopy sensor vegetation indices. Agronomy Journal 103:1815-26.

Soil Survey Staff, Natural Resources Conservation Service, United States Department of Agriculture. Web soil survey. http://websoilsurvey.nrcs.usda. gov/ (accessed November 7, 2012). 